\title{
UNA EXPERIENCIA PEDAGÓGICA DE LA ESCUELA NUEVA: CARMEN CONDE Y EL ORFANATO NACIONAL DE EL PARDO ${ }^{\alpha}$
}

\section{A pedagogical experience of the Progressive Education movement: Carmen Conde and the Orfanato Nacional de El Pardo (Spanish National Orphanage of El Pardo)}

\section{Javier Fernández Fernández ${ }^{\circledR}$}

Fecha de recepción: 15/12/2017 • Fecha de aceptación: 05/02/2018

Resumen. En este artículo se analiza la labor desarrollada por Carmen Conde en el Orfanato Nacional de El Pardo como inspectora-celadora de estudios entre octubre de 1934 y septiembre de 1935. En primer lugar, tras exponer la transformación que experimentó este centro en los primeros años de la Segunda República, se estudia la incorporación de Carmen Conde al Orfanato, su labor educativa y la conflictiva relación que mantuvo con los cargos directivos del centro, el patronato y el administrador-depositario, hasta su expulsión en el verano de 1935. En segundo lugar, se examinan los intentos por regresar al Orfanato tras la victoria electoral del Frente Popular en 1936 y su rivalidad con María Teresa Junquera para ocupar la dirección del establecimiento. En tercer lugar, se exponen las circunstancias de la producción y el contenido de su obra La composición literaria infantil: (escuela primaria), fruto de los ensayos que realizó en el Orfanato Nacional de El Pardo para mejorar la expresión oral y escrita de los acogidos. Por último, se analiza esta obra siguiendo la segunda versión de las treinta características de la Escuela Nueva redactadas por Adolphe Ferrière en 1925. Dichas características tratan tanto de la organización de las escuelas como de la vida física y la vida intelectual, así como de la educación social y la educación artística y moral.

Palabras clave: Carmen Conde; Orfanato Nacional de El Pardo; Escuela Nueva; Expresión oral; Expresión escrita.

\footnotetext{
${ }^{\alpha}$ El autor desea agradecer al Patronato Carmen Conde-Antonio Oliver y a su personal, especialmente a Caridad Fernández Hernández, toda la ayuda y colaboración prestada.

B Archivo General de Palacio, Patrimonio Nacional. Palacio Real, C/ Bailén, s/n, 28071 Madrid, España. javier.fernandez@patrimonionacional.es
}

Cómo citar este artículo: Fernández Fernández, Javier. «Una experiencia pedagógica de la escuela nueva: Carmen Conde y el Orfanato Nacional de El Pardo». Historia y Memoria de la Educación 10 (2019): 487-523 
Abstract. This article analyzes the work done by Carmen Conde at the Orfanato Nacional de El Pardo (Spanish National Orphanage of El Pardo) as inspector-overseer of studies between October of 1934 and September of 1935. Firstly, the article explains the transformation that this center had undergone in the early years of the Second Spanish Republic and examines the appointment of Carmen Conde at the Orphanage, her educational initiatives and the conflictive relationship with the management positions of the organization, the board and the administrator, until her removal in the summer of 1935. Secondly, the article studies her attempts to return to the Orphanage after the electoral triumph of the Popular Front during the winter of 1936 and the competition with Maria Teresa Junquera to lead the institution. Thirdly, the text exposes the circumstances of the creation and the content of her publication La composicion literaria infantil: (escuela primaria) (Literary creation for children: primary school), as a result of her attempts carried out in the Orfanato Nacional de El Pardo to improve the oral and written expression of the foster children. Finally, the paper enquires into this work and compares it to the second version of the thirty characteristics of the New Schools elaborated by Adolphe Ferrière in 1925. These characteristics have to do with the organization of the schools, physical life, intellectual life, social education and artistic and moral education.

Keywords: Carmen Conde; Orfanato Nacional de El Pardo; Progressive Education; Oral expression; Written expression.

La escritora Carmen Conde Abellán trabajó entre julio de 1934 y septiembre de 1935 como inspectora-celadora de estudios del Orfanato Nacional de El Pardo, centro anteriormente conocido como Asilos de San Juan y Santa María o de El Pardo. Fruto de su trabajo en El Pardo es una de sus pocas monografías pedagógicas, La composición literaria infantil: (escuela primaria), en la que se aúnan las dos pasiones de la poetisa: la educación y la escritura. El propósito de este artículo es analizar el paso de la escritora por el Orfanato y el estudio del ensayo que realizó para mejorar la expresión escrita y oral de los acogidos en El Pardo.

\section{EL ORFANATO NACIONAL DE EL PARDO}

Los Asilos de El Pardo, inaugurados en 1869, fueron una fundación del gobernador de la provincia de Madrid, Juan Moreno Benítez, para intentar acabar con la mendicidad en las calles de la capital. Acogían a niños, adultos y ancianos de ambos sexos. Estuvieron regidos por médicos hasta la década de 1920. Uno de ellos fue Alberto Giner Cossío, primo y discípulo de Francisco Giner de los Ríos. 
Tras unos años de absoluto abandono por parte de sus órganos rectores y el desamparo en el que se encontraban los asilados, intervino el ministro de la Gobernación Leopoldo Matos el 4 de febrero de 1931 declarando los Asilos como pertenecientes a la Beneficencia General del Estado. Asimismo, se nombró un patronato presidido por el ministro y formado por el decano de la Facultad de Filosofía y Letras de la Universidad Central, Manuel García Morente, el director del Laboratorio de Anatomía Microscópica de la Junta de Ampliación de Estudios, Luis Calandre Ibáñez, que actuaron como vocales, y el filántropo Juan de Selgas y Marín, como vocal-delegado. Estos tres hombres, con el apoyo del gobierno, transformaron entre febrero de 1931 y febrero de 1934 los viejos Asilos en una casa de huérfanos modélica, el Orfanato Nacional de El Pardo.

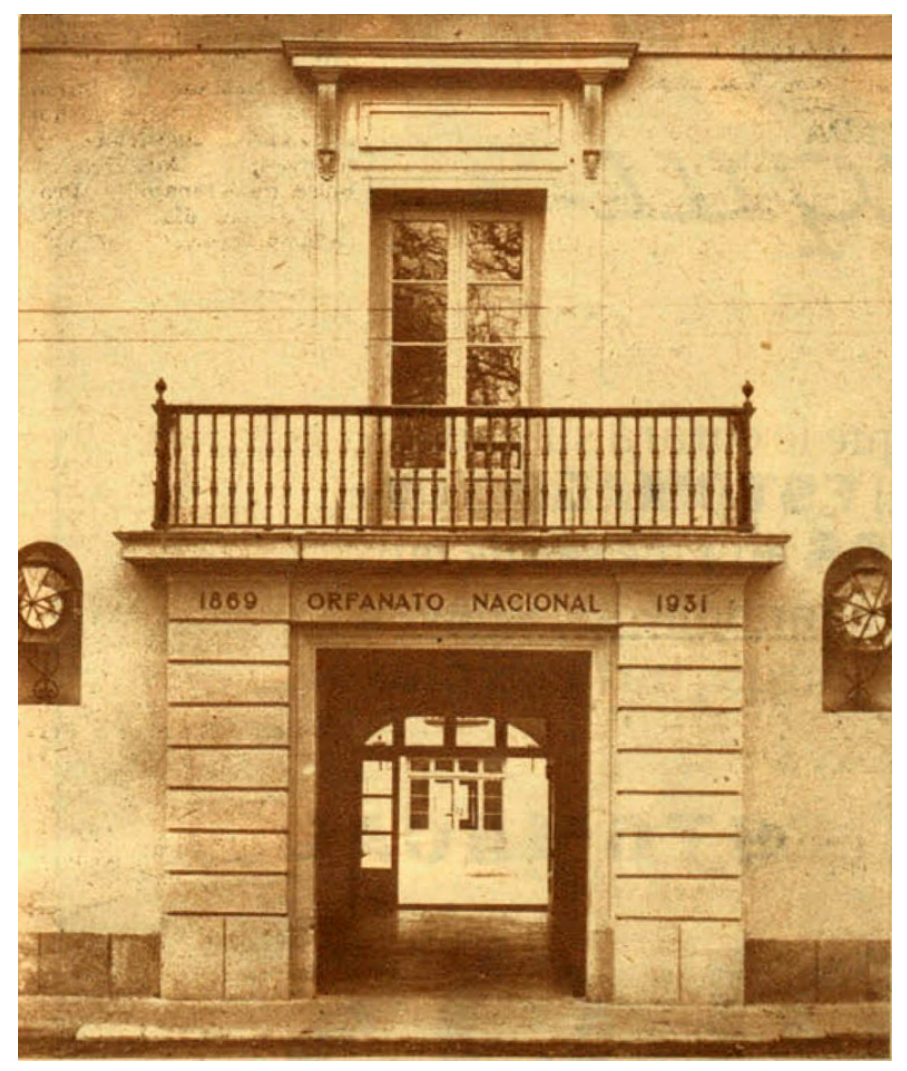

Imagen 1. Entrada principal del Orfanato Nacional de El Pardo (Foto Pando). ${ }^{1}$

\footnotetext{
1 «En breve se inaugurará el Orfanato Nacional de El Pardo», Ahora, 16 de diciembre de 1933, 27.
} 
Para ello, en primer lugar, tuvieron que trasladar a ancianos y anormales a otras instituciones más idóneas. En segundo lugar, realizaron un vasto plan de funcionamiento eficiente que tuvo como resultado la publicación del reglamento interior de 1931 y las obras de reforma y construcción de edificios para la instalación adecuada de los acogidos según las modernas normas higiénicas y pedagógicas. Y, en tercer lugar, hubo que reorganizar las enseñanzas de los acogidos, por lo que crearon un grupo escolar para niños, niñas y párvulos de ocho secciones, a cargo de un director de estudios y regido por el patronato, al igual que los patronatos escolares de Madrid, Barcelona y Zaragoza. Las escuelas estuvieron a cargo de maestros nacionales del escalafón general, seleccionados por el patronato. Para su dirección se escogió a Dionisio Correas, maestro de gran prestigio del grupo escolar La Florida, líder sindical de los maestros y consejero de Instrucción Pública. La dirección escolar tuvo que convivir con la dirección del resto de los servicios auxiliares en manos del administrador-depositario, Luis Carmona. La inauguración oficial fue el 22 de diciembre de 1933. Ya entonces Correas había sido sustituido por el maestro segoviano Pablo de Andrés Cobos. ${ }^{2}$

Carmen Conde conocía bien la transformación del Orfanato Nacional por su amistad con el doctor Calandre. Su marido, Antonio Oliver, escribió un artículo sobre el Orfanato en el diario $L u z,{ }^{3}$ y ella misma describió tiempo después la vida de que disfrutaban los niños durante esta etapa:

En otro tiempo, pese al sapito administrativo, las criadas hacían la limpieza de los niños todos; y ellos iban a clase, al sol del monte, se bañaban y duchaban, olían bien... Cuando salieran del «Asilo» verdad es que les aguardaba a todos la pobreza; pero también era cierto que a la pobreza llevarían un gran sentido de la higiene, de la belleza, y una cultura, una sensibilidad. ${ }^{4}$

\footnotetext{
2 Javier Fernández Fernández, «La construcción de una casa de huérfanos modélica, el Orfanato Nacional de El Pardo (febrero de 1931-febrero de 1934)» (Trabajo de Fin de Máster, Universidad de Alcalá, 2013), 60-120.

3 Antonio Oliver Belmás, «Una gran obra de beneficencia: El Orfanato Nacional de El Pardo», Luz: diario de la República (Madrid), 25 de octubre de 1933, 8-9.

${ }^{4}$ Carmen Conde, «IX. Orfanato (1934)», s.f., pp. 4-5, producción literaria-prosa, caja 2, Archivo Patronato Carmen Conde-Antonio Oliver (APCCAO).
} 
En febrero de 1934 dimitió el patronato por desavenencias con el ministro de Trabajo y Previsión Social, José Estadella, y la directora general de Beneficencia, Clara Campoamor. ${ }^{5}$ Fueron nombrados entonces vocales del patronato José Verdes Montenegro, a la sazón director general de Sanidad, y la escritora Concha Espina, mientras que Mario León, representante del Partido Radical en El Pardo, fue designado vocaldelegado.

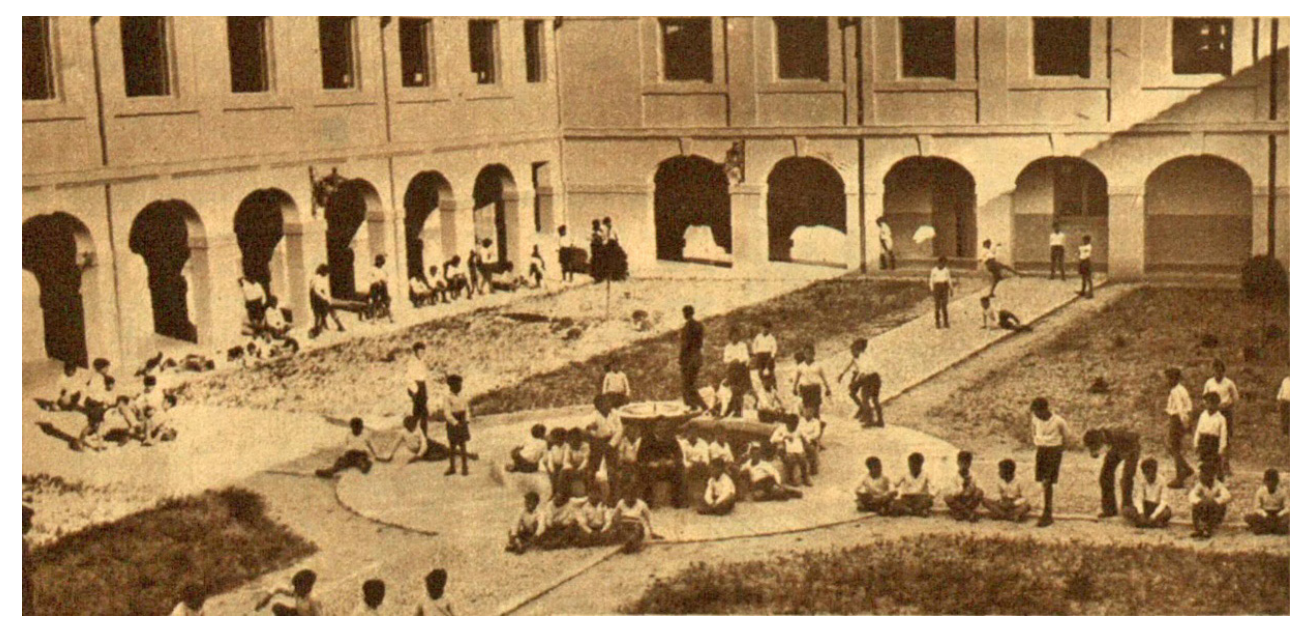

Imagen 2. «He aquí una vista del magnífico patio del pabellón de niños en el Orfanato Nacional de El Pardo [...]» [Foto Marina]. ${ }^{6}$

\section{CARMEN CONDE Y EL ORFANATO NACIONAL DE EL PARDO}

Carmen Conde inició pronto su andadura pedagógica. Cuando contaba con dieciséis años conoció en Cartagena al creador de las primeras escuelas graduadas de España, el maestro Enrique Martínez Muñoz, quien le recomendó estudiar Magisterio porque «sería una gran

\footnotetext{
${ }_{5}^{5}$ El patronato dimitió el 22 de febrero de 1934 por la revisión por parte del ministro Estadella de los ceses de los maestros de taller Guillermo López Ruiz y Laureano Páramo Cancel que ya habían sido autorizados por el anterior ministro competente, Manuel Rico Avello. Fueron despedidos por su participación política en El Pardo durante los días previos a las elecciones de noviembre de 1933. Por esta misma razón es obligado a dimitir el director de estudios Dionisio Correas. Los miembros del patronato entendieron que Estadella y Campoamor quebrantaban su autoridad moral. Unos días después, el 28 de febrero, el diario El Sol dedicó su editorial, titulado «Sabotaje político», al ataque cometido por el ministro sobre el patronato.
}

6 «Agua artesiana en El Pardo», Ahora, 8 de junio de 1935, 16. 
pedagoga».7 Por esa razón, comenzó sus estudios en la Escuela Normal de Maestras de Murcia en el año 1927, terminándolos tres años después en la de Albacete. ${ }^{8}$ Los problemas de la pedagogía social no le eran ajenos a Carmen Conde. Antes de la llegada de la Segunda República, había colaborado en Cartagena con la Asociación de las Hijas de María y con las hermanas de la caridad de la Casa de Misericordia. ${ }^{9}$ Además, en su primera obra sobre pedagogía, Por la escuela renovada, editada en 1931, manifiesta su interés por la educación de los niños de familias pobres. Por último, en julio de 1932 es nombrada vocal-maestra de la Junta Local de Protección a la Infancia y Represión de la Mendicidad de Cartagena, de la que dependía la Casa del Niño.

La incorporación de Carmen Conde al Orfanato Nacional de El Pardo parece un empeño personal de la propia Clara Campoamor. Su labor desarrollada en Cartagena debió de llegar a oídos de la directora general de Beneficencia, y en abril de 1934, Consuelo Berges, amiga de la poetisa que trabajaba por entonces en la dirección general de Beneficencia, le escribió anunciando que Campoamor había pensado en ella para dirigir el grupo escolar del Orfanato; cargo que resultó inviable porque la escritora no era maestra del escalafón:

Y a propósito: Clara que tiene unas intuiciones inesperadas, piensa en ti: un buen día me sorprendió con el propósito de traerte como Directora escolar del magnífico Orfanato del Pardo. Después ha surgido el inconveniente [...] de que el Orfanato, a los efectos docentes, esté considerado como grupo escolar cuyo personal se provee entre maestros del escalafón. ${ }^{10}$

Por esa misma razón tampoco pudo ocupar ninguna plaza de maestra. Existían varias vacantes porque en los primeros meses del año 1934

\footnotetext{
${ }_{7}^{7}$ Zenaida Gutiérrez-Vega y Marie-Lise Gazarian-Gautier, Carmen Conde, de viva voz, (Nueva York: Senda Nueva de ediciones, 1992), 30.

8 Pedro Luis Moreno Martínez, "Carmen Conde y una ilusión: la educación del pueblo», en Carmen Conde: voluntad creadora (1907-1996), ed. Francisco Javier Díez de Revenga (Murcia: Sociedad Estatal de Conmemoraciones Culturales-Ayuntamiento de Cartagena-Patronato Carmen Conde-Antonio Oliver, 2007), 99.

${ }_{9}$ Pedro Luis Moreno Martínez, Educación popular en la Segunda República Española: Carmen Conde, Antonio Oliver y la Universidad Popular de Cartagena (Madrid: Biblioteca Nueva, 2008), 232-244.

10 Consuelo Berges, «Carta a Carmen Conde», 19 de abril de 1934, caja 15 carpetilla 1460, (APCCAO).
} 
dimitieron o fueron cesados cinco de los ocho maestros del Orfanato nombrados en el verano de 1933. ${ }^{11}$ En este momento, la poetisa se encontraba trabajando como maestra interina en la Escuela unitaria de El Retén de las afueras de Cartagena.

A finales de mayo, Consuelo Berges escribió de nuevo a Carmen Conde informándole sobre una nueva propuesta de la directora general de Beneficencia. ${ }^{12}$ Clara Campoamor quería organizar colonias escolares de verano "para recoger unos cientos de niños más o menos vagabundos» en el monte de El Pardo o lugares similares, y había pensado en la escritora como maestra inspectora. Esto le permitiría a la cartagenera, según su amiga, "aprovechar el verano con una experiencia "benéfica" —aunque, claro está retribuida- y utilizable literaria, pedagógica y quizá burocráticamente para el futuro». Este proyecto tampoco fructificó por lo que la poetisa continuó en su escuela murciana.

Hubo que esperar hasta el verano para que se produjera una vacante en el Orfanato, circunstancia que aprovechó Clara Campoamor para nombrarla, seguramente sin conocimiento de la propia escritora, inspectora-celadora de estudios del mismo. ${ }^{13}$ Este cargo lo ocupaba desde enero de 1933 Aurora Pérez González, viuda del médico y diputado socialista José Sanchís Banús. El 21 de julio de 1934, Aurora dimitió y ese mismo día Carmen Conde recibió el nombramiento por parte de la directora general de Beneficencia. ${ }^{14}$ La escritora y su marido, Antonio Oliver, buscaban «una estabilidad futura». Por ello aceptó el trabajo «por compromiso, y por estar un tiempo en Madrid». ${ }^{15}$

El puesto de inspectora-celadora de estudios era anómalo ya que no figuraba en el reglamento en vigor, de julio de 1931. Para la labor educativa, esta norma estipulaba únicamente que los maestros fueran ayudados por los auxiliares. El empleo de inspectora-celadora de estudios, dotado

\footnotetext{
${ }^{11}$ Estaban vacantes dos plazas de maestras. La de Enriqueta Castellanos, que había dimitido junto con su marido el director de estudios Pablo de Andrés Cobos, y la de la maestra de párvulos, Francisca Gómez, que fue cesada junto con los maestros Ángel García y José Brocca.

12 Consuelo Berges, «Carta a Carmen Conde», 25 de mayo de 1934, caja 16 carpetilla 1530, (APCCAO).

${ }_{13}$ Carmen Conde, Por el camino, viendo sus orillas, vol. I (Barcelona: Plaza y Janés, 1986), 107.

14 «Expediente personal de Aurora Pérez González», 1933-1934, Orfanato Nacional de El Pardo-Colegio Los Lujanes, caja 377917 expediente 2, Archivo Regional de la Comunidad de Madrid (ARCM).

${ }_{15}$ María Cegarra Salcedo y Carmen Conde, Epistolario: 1924-1988 (Madrid: Torremozas, 2018), 442.
} 
de un sueldo de 6.000 pesetas anuales, se creó como puesto intermedio entre maestros y auxiliares, pero sin unas funciones reguladas. Da la impresión de que se creó expresamente para ayudar a Aurora Pérez, pues estaba a cargo de sus cuatro hijos huérfanos de padre. El reglamento de septiembre de 1934 sí recogía el cargo y fijaba que su deber era «la vigilancia de todos los servicios relacionados con la educación e instrucción extraescolar de los educandos», ${ }^{16}$ y para el correcto desempeño contaba con la ayuda de diez auxiliares a su cargo. Estos servicios eran fundamentales para realizar una educación integral y en la práctica consistían en el comedor - la disposición de las más de 20 mesas, la forma de servir las comidas, la cantidad de las raciones, la forma de comer y el tono de las conversaciones de los cerca de 300 huérfanos-, y la inspección de los alimentos y de los tiempos de estudio y de ocio, especialmente de todo lo relacionado con la lectura.

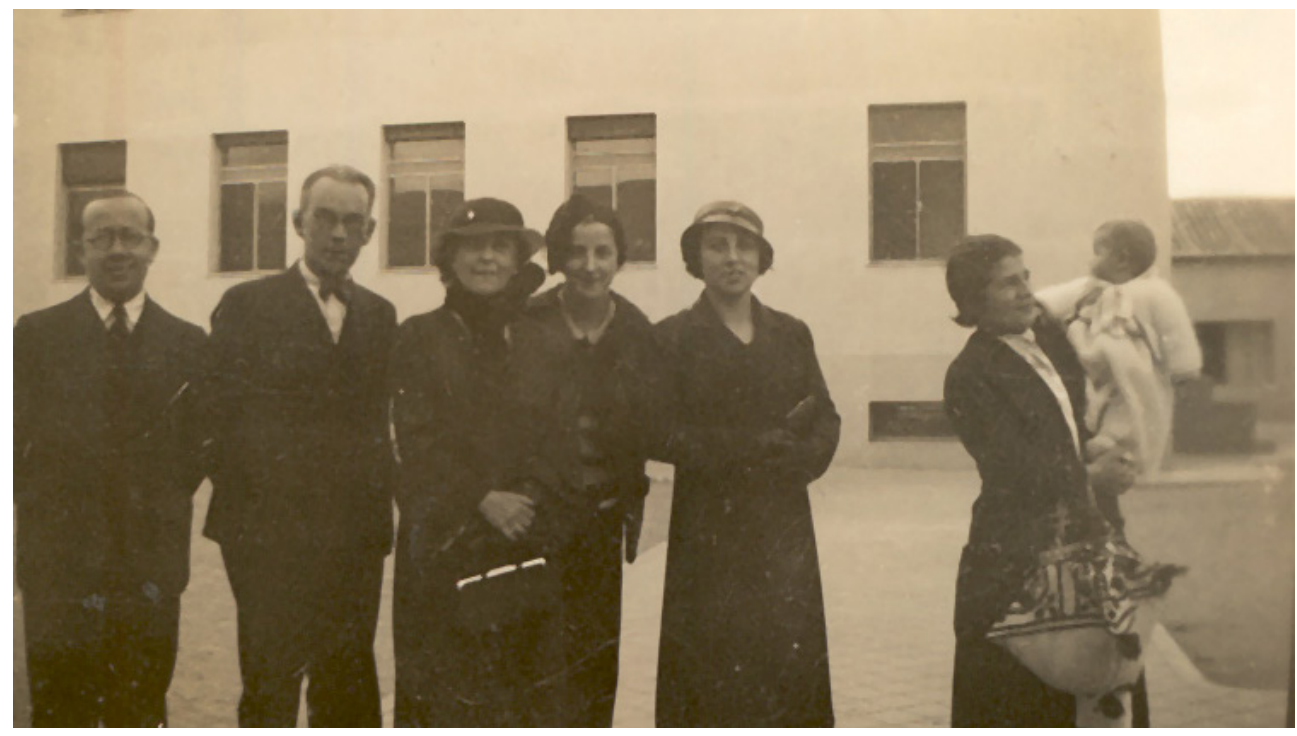

Imagen 3. De izquierda a derecha: Juan Camacho, director de estudios; Luis Carmona, administradordepositario; Concha Espina, vocal del patronato, acompañadas por Josefina Serna Espina y la hija de ésta, Paloma, en el Orfanato Nacional de El Pardo, 30 de octubre de 193417 (APCCAO).

${ }_{16}$ Ministerio de Trabajo, Sanidad y Previsión, «Orden aprobando el Reglamento interior, que se publica, de los Asilos de San Juan y Santa María (Orfanato Nacional) de El Pardo», Gaceta de Madrid (25 de septiembre de 1934).

${ }_{17}$ La visita de Concha Espina se produjo para dar respaldo a Carmen Conde ante los responsables del Orfanato. 
A pesar de que Carmen Conde recibió el nombramiento el 21 de julio, no fue hasta primeros de octubre cuando se incorporó, ya que los niños disfrutaban de una colonia escolar en la localidad guipuzcoana de Guetaria. Por ello, siguió trabajando en El Retén hasta finales de septiembre. Las primeras semanas fueron gratas para la escritora. En estos términos se manifestaba a su amiga María Cegarra: «es hermosa y prometedora la organización. A mí me gusta mucho el Orfanato».18

Carmen Conde contó con el apoyo del patronato, especialmente de Concha Espina. Mantuvo una relación más estrecha con la maestra responsable del gabinete psicotécnico del Orfanato, Dionisia Plaza Sánchez ${ }^{19}$, «viva, fina, y de simpatía». A los maestros y auxiliares masculinos los describía con estas palabras; «casi son grises todos; solo uno, de los últimos, [Santiago] Valle [García], es chico que vale y merece la atención». En cuanto a las auxiliares femeninas, «la mejor es una chica llamada Modesta [Viera Martínez], bonita y fina». Finalmente, respecto al alumnado decía: «Entre las niñas hay una huérfana, Vicenta, que me gusta por su bondad y su soledad absoluta; y hay muchísimos chicos hermosos, alegres, buenos y gratos». ${ }^{20}$

Al poco de su incorporación al Orfanato se produjeron tres fatales noticias para la escritora. Su padre, Luis Conde, falleció en noviembre en Cartagena, y al entrar la CEDA en el gobierno y tras la revolución de 1934 cesó Clara Campoamor, su principal valedora, como directora general de Beneficencia. El cambio en el ejecutivo provocó también el relevo del patronato del Orfanato por otros miembros más en sintonía con el partido de Gil-Robles. Se nombró vocal-delegado a José María Martínez Ortega, conde de Argillo y futuro consuegro del general Franco, y vocales a Matilde Rubio García, de Acción Popular, y Dionisio Gómez Herrero, fundador del Instituto Municipal de Puericultura de Madrid.

Este nuevo patronato tenía una visión muy distinta de la educación de los acogidos. Sus miembros pensaban que se engañaba a los huérfanos inconscientemente por pretender convertir «muchachos de clase

\footnotetext{
18 Cegarra y Conde, Epistolario, 444.

19 Trabajó en el Orfanato entre abril y diciembre de 1934. Al año siguiente fue pensionada por la Junta de Ampliación de Estudios para estudiar psicotecnia en Francia.

${ }^{20}$ Cegarra y Conde, Epistolario, 446.
} 
desheredada en señoritos». Como consecuencia, exponía el conde de Argillo, se fomentaba sin querer «el odio de castas latente y el estado de indisciplina, olvidando que en educación como en todas las leyes biológicas jamás obra a saltos la Naturaleza». Por ello, cambiaron la orientación pedagógica:

No para tiranizar, no para volver al apolillado Asilo español de triste recuerdo, sino para respetar la personalidad del niño — problema capital en régimen de internado- facilitándole medios para que surja y se vigorice en plena libertad; pero, suavemente, sin estridencias y dentro de un vivo realismo pedagógico. ${ }^{21}$

Esta nueva orientación pedagógica dada por el patronato y el administrador-depositario, Luis Carmona, «el personaje de corazón con verdín» en palabras de la escritora, crearon un ambiente rancio y rígido que dañaba la educación de los huérfanos:

Hiciéronse «reformas»: las duchas y baños que eran diarios, se suprimieron; los párbulos (sic) empezaron a bañarse arropados en ridículos bañadores de gruesa tela que les cubrían impidiendo el paso del agua a la carne. Los alumnos de las Escuelas de Artes y Oficios se vieron despojados de sus vocaciones; las niñas empezaron a aprender a ser criadas perfectas: sumisas ante todo. Y los niños fueron «disciplinados» por orden del corazón de verdín y de unos ridículos personajes gordos, con voces mujeriles, que andaban de acá y para allá estimulando el orden pero, en el fondo, desordenándolo todo; provocando el odio y el asco.

Ya se echaba a la calle a un grupo de muchachos sin familia, en la edad peor, de 15 a 20 años; sin oficio, sin casa donde ir, con un donativo de cinco duros tan solo. [...] Entretanto, los gordos que se decían amigos del Orden, empujaban al crimen y al vicio a aquellos infelices «asilados» expulsados injustamente. [...]

Las niñas estaban al cuidado de la limpieza otra vez; fregaban, lavaban, barrían, hacían camas. En una palabra: se ganaban

\footnotetext{
21 Orfanato Nacional de El Pardo, Memoria leída el día 8 de diciembre de 1935 por el Sr. Vocal-Delegado del Patronato de los Asilos de San Juan y de Santa María (Orfanato Nacional), ante el Excmo. Sr. Ministro de Trabajo, Justicia y Sanidad, con motivo de la instalación total de los mismos (El Pardo: Asilos de San Juan y Santa María [Orfanato Nacional], s.a.), 8.
} 
el sustento que el Estado pagaba, pagando además criados para ellas, cuyos salarios ahora... se economizaban. ${ }^{22}$

Carmen Conde que, al ser maestra de formación en ocasiones tuvo que sustituir a alguna de los docentes, se excedió en muchos casos en sus labores inspectoras especialmente sobre los alimentos y el funcionamiento del comedor para conseguir una mayor eficacia. Por ello chocó en varias ocasiones con el patronato y el administrador-depositario. A finales de enero de 1935 denunció deficiencias en las raciones y comidas que se repartían a los huérfanos y terminó siendo desplazada del servicio. ${ }^{23}$ En febrero, el patronato la despojó de la casa que disfrutaba en El Pardo, propiedad del Orfanato, porque estaba destinada a los maestros, por lo que tuvo que instalarse en una pensión en Madrid. Por otra parte, el patronato cedista, que veía innecesario su cargo, lo acabó eliminando en el nuevo reglamento de abril de 1935, ${ }^{24}$ en el que también cambiaba la denominación de los auxiliares a «inspectores-auxiliares», devaluando así las funciones de la inspectora-celadora de estudios. ${ }^{25}$

Durante el año escaso que la escritora trabajó en el Orfanato Nacional de El Pardo luchó contra ese ambiente insuflándole un espíritu nuevo que lo dulcificara, "promoviendo misiones pedagógicas, ${ }^{26}$ propugnando

\footnotetext{
22 Conde, «IX. Orfanato (1934)», 2-5. En el texto la escritora no cita otro de los cambios importantes que introdujo el patronato, la sustitución de las maestras y auxiliares por las Hermanas de la Caridad en la atención a las niñas y párvulos fuera de las aulas. El texto también narra la expulsión durante la Nochebuena de 1934 de seis niñas de las mayores tras pasar llorando parte de la noche como forma de protesta. Unos hechos similares fueron denunciados en el diario $\mathrm{La}$ Voz de 21 de diciembre de 1934.
}

${ }_{23}$ «Expediente personal de Carmen Conde», 1934-1935, Orfanato Nacional de El Pardo-Colegio Los Lujanes, caja 377917 expediente 45, ARCM.

${ }^{24}$ Ministerio de Trabajo, Sanidad y Previsión, «Reglamento interior de los Asilos de El Pardo, Establecimiento de Beneficencia general de San Juan y Santa María», Gaceta de Madrid (4 de abril de 1935).

25 Dentro del Orfanato se terminó llamando «inspectores» a los auxiliares e igualando sus cargos con el de la inspectora-celadora de estudios. En un oficio de enero de 1935 dirigido por José Martínez Ortega a Luis Carmona se equiparan estos cargos: «entre la referida doña Carmen y los demás Inspectores».

${ }_{26}$ Participó en las misiones de 1935 de espaldas al Orfanato. El 7 de marzo de 1935, Matilde Moliner secretaria accidental del Patronato de Misiones Pedagógicas comunicó a Carmen Conde y a su marido Antonio Oliver su nombramiento para dirigir su segunda misión pedagógica en la provincia de 
enseñanzas especiales, ejercicios de música, declamación y poesía, cine instructivo, amor al libro, etc. etc.».27 Este tipo de actividades fueron las que impulsó, junto con Antonio Oliver, desde la Universidad Popular de Cartagena o en las misiones pedagógicas que realizó en Murcia. En ese conjunto de acciones que buscaban dulcificar el ambiente del Orfanato se encuadra su obra La composición literaria infantil: (escuela primaria).
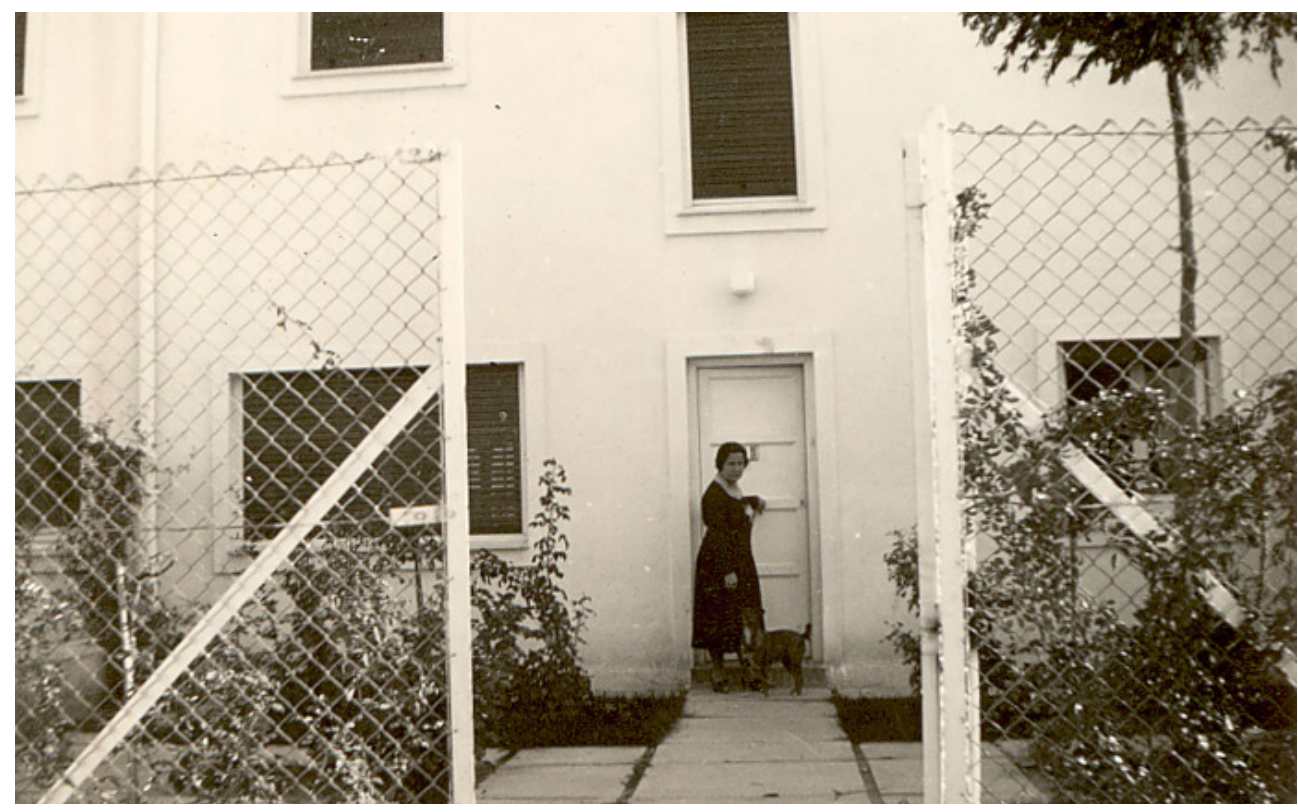

Imagen 4. Carmen Conde en el jardín de su casa junto al Orfanato Nacional de El Pardo, octubre de 1934. (APCCAO).

La pugna entre el patronato cedista y Carmen Conde terminó en el verano de 1935 con la expulsión de la escritora. A comienzos de agosto, la inspectora-celadora de estudios viajó sin permiso a Cartagena cuando

\footnotetext{
Murcia (Véase Moreno, Educación popular en la Segunda República Española. Carmen Conde, Antonio Oliver y la Universidad Popular de Cartagena, 217). El día siguiente Carmen Conde obtuvo un permiso de un mes por parte del director general de Beneficencia «con el fin de atender asuntos familiares urgentes». La misión se desarrolló entre los días 13 y 19 de marzo.

${ }_{27}$ Cita perteneciente al recurso de alzada que presentó Carmen Conde contra la orden de la Dirección General de Beneficencia que la declaró cesante. "Expediente personal de Carmen Conde», ARCM.
} 
tenía que hacerse cargo de un grupo de alumnas. ${ }^{28}$ Se desplazó para recuperarse de una enfermedad nerviosa y atender a su marido, Antonio Oliver, que padecía depresión..$^{29}$ Ante esta ausencia, el patronato le despidió a comienzos de septiembre. ${ }^{30}$

Tras las elecciones de febrero de 1936, en las que los partidos del Frente Popular derrotaron a las derechas, Carmen Conde se plantea intentar regresar a su puesto en el Orfanato Nacional de El Pardo ante el inminente final del patronato cedista. Únicamente habían pasado cinco meses desde su despido. Así lo manifiesta el día 20 de febrero a Zenobia Camprubí. ${ }^{31}$

Para conseguir la reposición en el Orfanato, Carmen Conde y Antonio Oliver contaron con la ayuda de amigos influyentes que residían en Madrid, en especial del abogado Andrés Conesa y del recién nombrado ministro de Agricultura, Mariano Ruiz-Funes. Conesa le informó el día 25 de febrero que había presentado la instancia en el Ministerio de Trabajo, Sanidad y Previsión solicitando su reincorporación. ${ }^{32}$ Es lo mismo que le recomienda Luis Álvarez Santullano ese mismo día. ${ }^{33}$

Dos días después, Conesa informa de la entrevista mantenida con el recién nombrado subsecretario de Sanidad y Beneficencia, Cándido Bolívar Pieltain, amigo suyo, y al que ha planteado la vuelta a El Pardo de la poetisa y la conveniencia de remover al patronato cedista del Orfanato. ${ }^{34}$ También el mismo 27 de febrero le escribe Domingo Barnés, nuevo subsecretario de Instrucción Pública y Bellas Artes, para anunciarle su interés: «Lo del Pardo, lo arreglaremos rápidamente con buena voluntad y creo que a satisfacción de las personas que, como V., la tienen tan

\footnotetext{
28 «Expediente personal de Carmen Conde», ARCM.

29 Antonio Oliver, «Carta a Juan Ramón Jiménez», 7 de septiembre de 1935, caja 60 carpetilla 100, (APCCAO).

30 Andrés Conesa, «Carta a Carmen Conde», 25 de febrero de 1936, caja 20 carpetilla 1971, (APCCAO).

${ }_{31}$ Carmen Conde, "Carta a Zenobia Camprubí», 20 de febrero de 1936, caja 60 carpetilla 89, (APCCAO).

32 Andrés Conesa, «Carta a Carmen Conde», 25 de febrero de 1936, caja 20 carpetilla 1971, (APCCAO).

33 Luis Álvarez Santullano, «Carta a Carmen Conde», 25 de febrero de 1936, caja 20 carpetilla 1970, (APCCAO).

${ }^{34}$ Andrés Conesa, «Carta a Antonio Oliver», 27 de febrero de 1936, caja 20 carpetilla 1973, (APCCAO).
} 
buena. Aún no he puesto manos en el asunto, pero las pondré pronto y procuraré que sea con la mayor eficacia y rapidez». ${ }^{35}$ El 28 de febrero es el ministro de Agricultura, Mariano Ruiz-Funes, el que le informa de que ya ha hablado de la vuelta de Carmen Conde con el ministro de Trabajo, Sanidad y Previsión, Enrique Ramos Ramos. ${ }^{36}$

A los pocos días, el 4 de marzo, el ministro de Trabajo, Sanidad y Previsión releva a los miembros del patronato del Orfanato. Tras el rechazo de Luis Calandre, Manuel García Morente y Juan de Selgas porque eran contrarios al modelo de «un Patronato de quita y pon» sujeto a los cambios de gobierno, ${ }^{37}$ se eligieron a otras personas también de corte liberal y relacionadas con el ambiente de la Institución Libre de Enseñanza. Se nombraron vocales a Margarita Rodríguez Velasco, profesora de la Escuela Normal de Santiago y directora entre 1929 y 1935 de la Residencia de niñas del Instituto-Escuela; Ramón María de Labra y Martínez, hijo del conocido antiesclavista y exrector de la Institución Libre de Enseñanza Rafael María de Labra; Guillermo Angulo Pastor, profesor de la Escuela Nacional de Puericultura; Aurora Pérez González, la predecesora de Carmen Conde como inspectora-celadora de estudios; y José Giner Pantoja, hijo de Alberto Giner Cossío y profesor de la Institución Libre de Enseñanza, que fue designado vocal-delegado. ${ }^{38}$

Andrés Conesa se dirigió rápidamente hacia los nuevos miembros del patronato. El 9 de marzo escribe a Antonio Oliver pidiendo el envío de la memoria que Carmen Conde redactó para José María Martínez Ortega el 28 de febrero de 1935, puesto que Aurora Pérez se había interesado por la restitución de Carmen Conde. La viuda de Sanchís Banús le pidió a Conesa este documento para que «entre otros elementos de juicio, permitirá formar un concepto adecuado de Carmen» y prometió hacer lo que estuviera en su mano, que era mucho. ${ }^{39}$

\footnotetext{
35 Domingo Barnés, «Carta a Carmen Conde», 27 de febrero de 1936, caja 20 carpetilla 1974, (APCCAO).

36 Mariano Ruiz-Funes, «Carta a Carmen Conde», 28 de febrero de 1936, caja 20 carpetilla 1975, (APCCAO).

${ }^{37}$ Luis Calandre, «Carta a Antonio Oliver», 25 de febrero de 1936, caja 12 carpetilla 1156 y «Carta a Antonio Oliver», 13 de marzo de 1936, caja 12 carpetilla 1159, (APCCAO).

${ }^{38}$ Presidencia de la República, «Decreto nombrando los miembros de la Junta de Patronato del Orfanato Nacional de El Pardo», Gaceta de Madrid (5 de marzo de 1936).

39 Andrés Conesa, «Telegrama a Antonio Oliver», 9 de marzo de 1936, caja 20 carpetilla 1977 y «Carta a Antonio Oliver», 10 de marzo de 1936, caja 20 carpetilla 1978, (APCCAO).
} 
BXCMO. SR. MINISTRO DE TRABAJO Y SAMIDAD.

Imagen 5. Copia de la instancia presentada por Carmen Conde para reingresar en el cargo de inspectora-celadora de estudios del Orfanato Nacional de El Pardo. 25 de febrero de 1936 (APCCAO).

Según pasan los días se ve que Carmen Conde tiene cada vez más dudas sobre la conveniencia de volver al Orfanato; así lo confesaba el 6 de marzo a su amiga Amanda Junquera: 
No sé si me devolverán el empleo de El Pardo, en el fondo, aparte de la satisfacción moral de la rehabilitación, no me gusta ir a enterrarme a un país de tapiz. Tengo demasiadas amistades en Madrid y me pasaría la vida en el camino. Pero si se resuelve bien esto, iré en poco tiempo y luego pediré la excedencia o lo dejaré. Estoy convencida de que no puedo vivir sin el mar. ${ }^{40}$

Por otra carta a la misma destinataria, ${ }^{41}$ sabemos de la existencia de otra candidata al mismo puesto, María Teresa Junquera, médico y enfermera. Durante sus estudios en Madrid fue residente en la Residencia de Señoritas y durante los cursos 1921-1922 y 1923-1924 fue alumna de prácticas del doctor Calandre en el Laboratorio de Anatomía Microscópica de la Junta de Ampliación de Estudios. ${ }^{42}$ Con los años fue vicesecretaria de la Asociación de Médicos Españolas desde 1928; subdirectora de un internado, el de la Escuela de enfermeras de la Casa de Salud Valdecilla entre 1929 y 1930, y participante en la misión pedagógica de Degaña en 1932, junto con Alejandro Casona. ${ }^{43}$

Ante la dura competencia que existía con María Teresa Junquera, el 14 de marzo, Andrés Conesa urgía a Carmen Conde la redacción de una memoria «muy detallada y documentada acerca de sus planes referentes al Orfanato, tanto de organización como de métodos pedagógicos a emplear», y su presencia en Madrid con la memoria para reclamar la plaza. Además, le pedía que gestionase la intervención de Calandre «para que personalmente, y silenciándole la intervención lograda de la Vda. de Sanchís Banús, gestione la reposición de Carmen». ${ }^{44}$ La recepción de esta carta suscitó que la escritora se plantease la renuncia, no quería

\footnotetext{
40 Carmen Conde, «Carta a Amanda Junquera», 6 de marzo de 1936, caja 19 carpetilla 1821, (APCCAO).

${ }^{41}$ Carmen Conde, «Carta a Amanda Junquera», marzo de 1936, caja 19 carpetilla 1832, (APCCAO).

42 Junta de Ampliación de Estudios, Memoria correspondiente a los cursos 1922-23 y 1923-24 (Madrid: Junta de Ampliación de Estudios, 1925): 257-258.

${ }^{43}$ Amiga de Matutina Rodríguez, hermana de Alejandro Casona, está considerada como una de las posibles fuentes de inspiración del personaje de Natalia Valdés de Nuestra Natacha por los problemas a los que se enfrentó en la Escuela de enfermeras. Véase Carmen Chamizo Vega, «El proceso de profesionalización de la enfermería en el Principado de Asturias» (Tesis doctoral, Universidad de Alicante, 2009), 111-117, y Residencia de Estudiantes, «Ficha de misionera pedagógica de María Teresa Junquera», Las Misiones Pedagógicas, 1931-1936. http://cipres.residencia.csic.es/misiones/ ficha_participante.php?id_persona=33\&nombre=\&apellido=junquera.
}

${ }_{44}$ Andrés Conesa, «Carta a Antonio Oliver», 14 de marzo de 1936, caja 20 carpetilla 1979, (APCCAO). 
intrigar y sí seguir viviendo en Cartagena. Así se expresó a Amanda Junquera el día 16:

yo no quiero luchar con nadie para la posesión de nada, aunque sea un hecho material y beneficioso para mí que nada tengo. He escrito a Aurora [Pérez] diciéndole que solo necesito mi rehabilitación moral, y que aparezca en ese horrendo órgano ministerial de la Gaceta; de mi plaza que disponga la Política, pues yo no tengo ganas de intrigar; y le he adjuntado mi dimisión, firmada, con la fecha en blanco. Cuando me repongan, cumpliendo el justo proceder, -lo único que vale-, ahí tienen mi renuncia para todo. Por ahora quiero vivir aquí [Cartagena]; más lejos, no me interesa. ${ }^{45}$

Llama la atención la exigencia de esta memoria sobre organización del Orfanato para candidatas a ocupar el puesto de inspectora-celadora de estudios, de nivel inferior al de maestro. Conesa explica en otra carta del día 17 que seguramente la plaza de inspectora-celadora de estudios no vuelva a reponerse en el Orfanato, por lo que, guiado por Aurora Pérez, está intentando que Carmen ocupe un puesto de mayor nivel al que tuvo:

Esa persona, por el gran interés que tiene en servirme, está haciendo en favor de Carmen todo lo posible y sólo se trata de obtener un apoyo documental de méritos que hagan su labor más sencilla, ya que ella no quiere aparecer como que apadrina ninguna candidatura. Esta gestión, unida a la intervención de Calandre, puede ser decisiva. Por tanto, entiendo que sólo es procedente obrar como yo aconsejaba en mi otra carta. ${ }^{46}$

El nuevo patronato pretendía mejorar la organización de la institución. Algunos de los cambios que se estaban barajando era la creación del cargo de director como jefe de todos los servicios y dependencias; esto es, por encima tanto del administrador-depositario como del director de estudios. Así se acabarían con los constantes enfrentamientos entre el administrador-depositario, jefe de todos los servicios, y el director

\footnotetext{
${ }_{45}$ Carmen Conde, «Carta a Amanda Junquera», 16 de marzo de 1936, caja 19 carpetilla 1822, (APCCAO).

46 Andrés Conesa, «Carta a Antonio Oliver», 17 de marzo de 1936, caja 20 carpetilla 1996, (APCCAO).
} 
de estudios, jefe de la parte educativa, que comenzaron en 1931. Para solucionar este problema el patronato destituyó al administrador-depositario Luis Carmona sustituyéndole por Luis Sánchez Cuesta, hermano del conocido librero León Sánchez Cuesta, y creó la plaza de director.

Como se puede comprobar por el nuevo reglamento interior aprobado en junio de 1936, era para la plaza de director para la que estaba haciendo las gestiones Conesa. Según este reglamento, que tampoco incorporaba el cargo de inspector-celador de estudios, la selección del director se llevaría a cabo mediante un concurso de méritos entre individuos de ambos sexos de más de treinta años, con título académico, que hayan prestado servicios en instituciones similares. Además, se requería de los candidatos la presentación de una «Memoria sobre funcionamiento y organización del Orfanato». De esta manera se buscaba que la dirección recayese en un educador. ${ }^{47}$

La nueva carta de Conesa parece que hizo que Carmen se replantease su renuncia. Intentó obtener la ayuda de Calandre, pero él respondió el 10 de abril que le gustaría ayudarle, pero que habiendo rechazado volver al patronato del Orfanato Nacional de El Pardo «no está bien ninguna intervención mía en algo que a él se refiere» ${ }^{48}$. Esta es la última carta que se conserva en el Archivo del Patronato Carmen Conde-Antonio Oliver sobre la vuelta de la poetisa a El Pardo. No sabemos si llegó a redactar la memoria sobre el funcionamiento y organización del Orfanato. De haberlo hecho, éste sería un documento fundamental para conocer el pensamiento pedagógico de la escritora cartagenera.

Finalmente, esta pugna entre María Teresa Junquera y Carmen Conde se resolvió a favor de la primera, pero no tomó posesión como directora interina hasta finales de julio de 1936 por lo que poco pudo hacer al

\footnotetext{
47 Ministerio de Trabajo, Previsión y Sanidad, «Orden aprobando el proyecto de Reglamento interior para el Orfanato Nacional de El Pardo (Asilos de San Juan y Santa María)», Gaceta de Madrid (13 de julio de 1936).

${ }^{48}$ Luis Calandre, "Carta a Carmen Conde», 4 de abril de 1936, caja 12 carpetilla 1160, (APCCAO). Esta negativa apoya la idea de que Calandre tampoco realizó gestión alguna en 1934 para el ingreso de Carmen Conde en el Orfanato. Por otra parte, se hacía difícil la intervención de Calandre, pues también le unía una amistad con María Teresa Junquera. Calandre recurrió a ella en 1932 para pedirle documentación cuando fue nombrado jefe de estudios del Hospital Escuela de Enfermeras de la Cruz Roja en Madrid. Véase José Manuel Sebastián Raz, «Luis Calandre Ibáñez. Su vida y obra (reivindicación de una figura ilustre de la medicina murciana)» (Tesis doctoral, Universidad de Murcia, 2010), 338-340.
} 
frente de la institución. ${ }^{49}$ La guerra civil española acabó con esta experiencia educativa destacada, como lo hizo con cientos más.

\section{LA COMPOSICIÓN LITERARIA INFANTIL: (ESCUELA PRIMARIA) \\ Características y publicación de la obra}

Desde octubre de 1934 sabemos que Carmen Conde trabajaba en la biblioteca con los niños. ${ }^{50}$ La composición literaria infantil: (escuela primaria) es el programa de enseñanza que Carmen Conde formuló y experimentó durante 1935 en el Orfanato Nacional de El Pardo para mejorar la expresión verbal y escrita de los niños. ${ }^{51}$ En ese momento, el nivel de los niños del Orfanato en lengua española era bajo, por ello, en marzo de 1935 la junta de maestros acordó establecer «el lenguaje o lectura y escritura como centro de interés de todas las clases».52

En La composición literaria infantil juegan un papel fundamental el cuento, para desarrollar la imaginación de los alumnos, y el dibujo, como medio de aprendizaje y expresión. En 1931 ya abogaba la escritora por que el maestro trabajara la expresión verbal del alumno, defendía que las nuevas corrientes pedagógicas exigían al educador "que haga hablar al niño", e insistía en que el maestro debía "obligar a hablar a sus discípulos». ${ }^{53}$

Tras su salida del Orfanato, Carmen Conde adaptó y ensayó el programa a la enseñanza de adultos, primero, en la Universidad Popular de Cartagena durante el curso 1935-1936; ${ }^{54}$ y, durante 1937, en la Casa de

\footnotetext{
49 «Expediente personal de María Teresa Junquera», 1936, Orfanato Nacional de El Pardo-Colegio Los Lujanes, caja 377916 expediente 58, ARCM.

${ }^{50}$ El 28 de octubre escribió a María Cegarra que, tras una fiesta, «los mayores -chicos de veinte añoshan ido con un auxiliar a dar vueltas por el pueblo (cinco calles hacia el río), y los párvulos a su clase, a jugar; con los medianos y medianas me he quedado yo en la Biblioteca, de cinco y media a ocho». Cegarra y Conde, Epistolario, 445.

${ }^{51}$ Carmen Conde, La composición literaria infantil: (escuela primaria) (Barcelona: Mujeres Libres, 1937), 14.

52 «Libro de actas de la junta de maestros», 1935-1975, fol. 1, Orfanato Nacional de El Pardo-Colegio Los Lujanes, caja 377850 expediente 1, ARCM.

${ }_{53}$ Carmen Conde, Por la escuela renovada (Murcia: Universidad de Murcia, 1978), 29-30.

${ }^{54}$ Se llamó «Literatura y Composición». Carmen Conde, «Una clase-ensayo», Presencia. Cuaderno de afirmación de la Universidad Popular 4 (1936): 9.
} 
la Mujer de Murcia, perteneciente a la Agrupación de Mujeres Antifascistas. ${ }^{55}$ Como se puede ver en los programas que de ambos cursos se conservan en el Archivo del Patronato Carmen Conde-Antonio Oliver, en estos ensayos para adultos se añadió la historia de la literatura clásica y castellana «con el estudio de los escritores y sus escuelas más notables». ${ }^{56}$

El propósito que seguía Carmen Conde con estos cursos de composición literaria era reunir los conocimientos de que disponían los alumnos y darles "cauce en donde verterse», ya que era indispensable que los alumnos «sepan escribir ordenada y claramente, con soltura y hasta elegancia, aquellos temas de sus estudios o documentos que precisen de su buena redacción». ${ }^{57}$

Consideraba la escritora que el desarrollo de la imaginación era una necesidad imperiosa para las clases populares, ya que en ellas lo que primaba era el sentido práctico, «el instinto defensivo, la preocupación social». ${ }^{58}$ Con los niños se estimularía la imaginación por medio de lecturas, adivinanzas, conversaciones, cuentos y películas de misterio, aventuras, etc. Además, recomendaba la serie de cortometrajes de dibujos animados de Walt Disney Sinfonías inocentes o Silly symphonies. ${ }^{59}$

Entre 1935 y 1937 siguió trabajando en la redacción definitiva de $L a$ composición literaria infantil, pidiendo opinión a sus amigos pedagogos. Uno de ellos fue Luis Álvarez Santullano, secretario del patronato de Misiones Pedagógicas, quien en mayo de 1936 recibió el programa para su lectura reposada. ${ }^{60}$ Finalmente, la obra se publicó en Barcelona en 1937 por el comité obrero Avant, perteneciente a la asociación

\footnotetext{
55 Moreno, «Carmen Conde y una ilusión: la educación del pueblo», 110.

56 Conde, «Una clase-ensayo», 9.

${ }^{57}$ Conde, «Una clase-ensayo», 9.

58 Conde, «Una clase-ensayo», 9.

59 Conde, La composición literaria infantil, 24 y 11. La serie se compone de setenta y cinco cortometrajes editados entre 1929 y 1939, entre los que destacan El baile de los esqueletos (1929), Los tres cerditos (1933), La cigarra y la hormiga (1934), El lobo feroz (1934), La liebre y la tortuga (1935) o El patito feo (1939).

${ }^{60}$ Luis Álvarez Santullano, «Carta a Antonio Oliver y Carmen Conde», 19 de mayo de 1936, caja 25 carpetilla 2421, (APCCAO).
} 
anarcosindicalista y feminista Mujeres Libres. El hecho de haber sido editada durante la guerra civil por una organización del bando vencido ha provocado que hoy sean pocas las bibliotecas que conservan ejemplares.

La composición literaria infantil está estructurada en doce puntos y tiene una extensión de treintaisiete páginas. Podemos distinguir claramente tres partes. La primera es una exposición esquemática del programa. Le siguen los complementos al programa y varios modelos de diario de clase, ficha escolar y cuaderno de trabajo del maestro. Finalmente, el núcleo de la publicación consiste en la explicación detallada de cada uno de los doce puntos. El programa comienza con el maestro narrando y dibujando en la pizarra un cuento mientras los niños lo observan atentamente. Concluye el curso con la elaboración y exposición por parte de los alumnos de trabajos grupales e ilustrados, previa consulta de material bibliográfico.

Carmen Conde propone organizar las clases con quince alumnos como máximo, y si nos atenemos al plan de distribución de tiempo y trabajo aprobado por la junta de maestros del Orfanato para el verano de 1935, las clases de composición tenían una duración de media hora y únicamente se impartían dos veces a la semana. ${ }^{61}$

\section{Análisis de las treinta características de las «escuelas nuevas» en La composición literaria infantil}

Ya que los orfanatos eran un tipo singular de «escuelas nuevas» vamos a analizar el grado de cumplimiento de sus treinta características en La composición literaria infantil. Adolphe Ferrière, director de la Oficina Internacional de Escuelas Nuevas, fijó las treinta características que representaban la esencia de este tipo de escuelas y constituían el programa máximo al que debían aspirar estos centros.

Ferrière redactó una primera versión que apareció en el prefacio a la obra de Antonio Faria de Vasconcelos Une école nouvelle en Belgique publicada en Neuchâtel (Suiza) en 1915. Ahí, Ferrière se limitó a

\footnotetext{
${ }^{61}$ Martes y sábados de 10:45 a 11:15. «Libro de actas de la junta de maestros», 1935-1975, fols. 2627, Orfanato Nacional de El Pardo-Colegio Los Lujanes, caja 377850 expediente 1, ARCM.
} 
registrar esas características que había analizado a través de su «experiencia de más de quince años, residencias prolongadas y frecuentes en muchas Escuelas Nuevas auténticas, numerosas comparaciones de hechos y de métodos, un estudio minucioso de sus resultados en los niños».62 Esta versión se difundió en español gracias a la traducción que Domingo Barnés hizo de la obra de Faria de Vasconcelos en 1920.

Ferrière redactó una segunda versión en 1925 para la revista Pour l'Ère Nouvelle: revue internationale d'éducation nouvelle, ${ }^{63}$ de la que era redactor jefe. Fue traducida por Rodolfo Tomás y Samper en 1928 para el prólogo de la obra del propio pedagogo suizo La práctica de la escuela activa: experiencias y orientaciones ${ }^{64}$ Allí expuso que el programa mínimo que debía cumplir una «escuela nueva» para ser considerada como tal era únicamente que fuera un

internado familiar situado en el campo, en el cual la experiencia personal del niño constituya la base tanto de la educación intelectual —utilizando particularmente los trabajos manuales — ${ }^{65}$ como la educación moral, practicando el sistema de la autonomía relativa de los escolares. ${ }^{6}$

El contenido de las dos versiones, como no podía ser de otro modo, es muy parecido. En la primera, cada uno de los caracteres se desarrolla en un párrafo. Mientras que, en la segunda se dividen generalmente en tres subpuntos y se articulan en cinco epígrafes ("ORGANIZACIÓN», "VIDA FÍSICA», «VIDA INTELECTUAL», «EDUCACIÓN SOCIAL» $\mathrm{y}$ «EDUCACIÓN ARTÍSTICA Y MORAL»).

Carmen Conde se formó en los años en que las teorías de la Escuela Nueva estaban en su apogeo. Terminó sus estudios de Magisterio en 1930 y al año siguiente comenzó a trabajar como auxiliar en la Escuela

\footnotetext{
${ }^{62}$ A. Faria de Vasconcelos, Una escuela nueva en Bélgica (Madrid: Francisco Beltrán, 1920).

${ }_{63}$ Adolphe Ferrière, «L“'École nouvelle” et le Bureau International des Écoles nouvelles», Pour l'Ėre nouvelle 15 (1925): 2-8.

${ }^{64}$ Adolphe Ferrière, La práctica de la escuela activa: experiencias y actuaciones (Madrid: Francisco Beltrán, 1928), 17-25.

${ }^{65}$ Hemos recuperado la cursiva para «trabajos manuales» que en la traducción de Tomás y Samper se perdió.

${ }^{66}$ Ferrière, La práctica de la escuela activa, 25.
} 
de El Retén y publicó su principal obra pedagógica, Por la escuela renovada. Ésta era una recopilación de once ensayos que había publicado en el diario Informaciones en los que se apostaba por la transformación de la escuela. Esta obra está impregnada de algunos de los postulados del movimiento de la Escuela Nueva, como el conocimiento del niño.

Los aspectos organizativos de la escuela constituyen prácticamente el programa mínimo de una «escuela nueva». Aunque Carmen Conde no los tratara en su obra, vamos a examinar cuáles observaba el Orfanato Nacional de El Pardo. La propiedad primera define las escuelas nuevas como laboratorios de pedagogía práctica:

1. La Escuela nueva es un Laboratorio de pedagogía práctica.

A. Como reformadora de las Escuelas del Estado, la Escuela nueva prepara el terreno demostrando la eficacia de los métodos nuevos.

B. Esta Escuela se basa en los datos de la psicología del niño y en las necesidades de su cuerpo y de su espíritu.

C. Trata de preparar a los niños para la vida moderna con sus exigencias materiales y morales.

Para responder si el Orfanato Nacional cumplía o no esta característica nos remitimos a la carta que Luis Calandre, vocal y representante del ministerio de Instrucción Pública y Bellas Artes en el patronato, escribió a Pablo de Andrés Cobos, exdirector de estudios. En ella, Calandre expresó el empeño que siguió el patronato de realizar «un ensayo pedagógico y social de amplio horizonte, abierto a todas las posibilidades». ${ }^{67}$ El fin que siguió este patronato fue convertir el Orfanato Nacional en un centro modelo para otros. No podemos asegurar que lo entendieran así los dos patronatos con los que trabajó Carmen Conde. De la actuación del patronato nombrado por Clara Campoamor en marzo de 1934 poco sabemos por el corto tiempo que desarrolló su labor, mientras que el patronato cedista no entendió la labor educativa y social del mismo modo que el primero.

\footnotetext{
${ }^{67}$ Luis Calandre, «Carta a Pablo de Andrés Cobos», 23 de agosto de 1934, Archivo Personal de Enri-
} queta Castellanos Pereda (APECP). 
El segundo rasgo de una «escuela nueva» es ser un internado:

2. La Escuela nueva es un Internado.

A. Únicamente la influencia total del medio permite realizar una educación integral.

B. La Escuela nueva se dirige, sobre todo, a los niños cuya familia no existe o no puede dirigir su educación según las exigencias de la ciencia moderna.

C. Tiende a servir de puente entre la vida familiar y la vida social, al permitir que los niños se agrupen por «familias» adoptivas según sus afectos espontáneos.

El Orfanato Nacional de El Pardo era un internado de niños y niñas desamparados o de familias pobres al que se quiso dotar de un ambiente familiar. Los maestros tenían la obligación de extender su influjo educativo a la vida total del niño, aseo, comidas, dormitorios, juegos, paseos, vida social, y no solamente a lo puramente escolar.

Carmen Conde era partidaria de este tipo de escuelas en el caso de que las familias fuesen un mal influjo para los niños. Así, en Por la escuela renovada, abogó por la necesidad de crear internados, con todos los adelantos pedagógicos para que vivan en ellos «los niños que tienen la desgracia de no poderse honrar» con el contacto de familias morales. ${ }^{68}$

La tercera característica de una «escuela nueva» es que está ubicada en el campo:

3. La Escuela nueva está situada en el campo.

A. El campo es el medio natural del niño. Allí encuentra la calma que necesita su sistema nervioso.

B. Posibilidad de entregarse a las distracciones de los hombres primitivos y a los trabajos de los campos.

C. Para los adolescentes, la proximidad de una ciudad es conveniente para la educación intelectual y artística (museos, conciertos, etc.).

\footnotetext{
${ }_{68}$ Conde, Por la escuela renovada, 55.
} 
También encontramos esta característica en el Orfanato Nacional. El Pardo era un pequeño pueblo y el Orfanato se encontraba inmediato al palacio ubicado en la localidad, pero también junto al monte. Como el propio Cobos escribió: «Donde acaba el Orfanato, comienza el monte de El Pardo, limpio, soberbio, clásico, bajo el cielo azul de Castilla».69 Además, se estableció un taller de jardinería y una granja avícola en 1935.70 Por último, dada su proximidad con Madrid, se realizaban excursiones a la capital.

La cuarta propiedad de una «escuela nueva» es que agrupa a los discentes en casas separadas:

4. La Escuela nueva agrupa a sus alumnos en casas separadas.

A. Los grupos de diez a quince alumnos viven bajo la dirección material y moral de un educador y de una educadora.

B. El elemento femenino no debe excluirse de la educación de los muchachos ni el elemento masculino de la educación de las muchachas.

C. Los hábitos de orden y las relaciones de intimidad no son posibles más que en un medio reducido.

Este punto no se cumplió puesto que los huérfanos se alojaban en dos grandes edificios dieciochescos levantados para ofrecer servicios auxiliares a la Corte durante las jornadas reales de invierno. Los niños ocupaban las antiguas Caballerizas Reales o Ballestería, mientras que las niñas dormían en el viejo Cuartel de Guardias de Corps. Ello provocó que los dormitorios fueran grandes y albergaran decenas de camas cada uno.

La quinta cualidad hace referencia a la práctica de la coeducación:

5. La Escuela nueva practica corrientemente la coeducación de los sexos.

\footnotetext{
${ }^{69}$ Pablo de A. Cobos, Orfanato Nacional de El Pardo: [tres meses de director de estudios] (Segovia: Imp. Carlos Martín, 1934), 6.

70 «Expediente de Obras de construcción de pabellones para granja avícola», 1935, Orfanato Nacional de El Pardo-Colegio Los Lujanes, caja 377806 expediente 1, ARCM.
} 
A. Reunidos desde su más tierna infancia, pero siendo educados según las necesidades particulares de su sexo, los muchachos y las muchachas viven como compañeros.

B. Los elementos que no convienen a la coeducación o a quienes la coeducación no conviene se excluyen.

C. Evitando los «retrocesos» patológicos, la coeducación prepara matrimonios sanos y felices.

La coeducación parece que se practicó durante el tiempo que ejerció la dirección del grupo escolar Pablo de Andrés Cobos; esto es, entre diciembre de 1933 y febrero de 1934. El 13 de diciembre de 1933 fue el día que los cerca de 200 acogidos que había entonces ocuparon las nuevas instalaciones del Orfanato Nacional de El Pardo tras año y medio de obras. Se abrieron seis clases (una de párvulos, dos mixtas, una para las huérfanas de más de catorce años, y dos para los huérfanos mayores de catorce). Practicaban, pues, la coeducación los párvulos y los menores de catorce años. Los tres grupos de mayores únicamente se juntaban en los patios, el comedor, las salas de recreo y los paseos. ${ }^{71}$ Cuando llegó Carmen Conde al Orfanato se llevaba a cabo ya dicha práctica, aunque las fuentes de este momento no aclaran si también se practicó en las clases de los mayores. Tras el nombramiento del patronato de la CEDA, se puso fin a la coeducación. ${ }^{72}$

\footnotetext{
71 Cobos, Orfanato Nacional de El Pardo, 9 y 25.

72 El maestro Juan Camacho Castro, que trabajó en el Orfanato Nacional entre el verano de 1933 y 1937 y fue su director de estudios entre marzo de 1934 y marzo de 1935, responde a las acusaciones de ser partidario de la coeducación lo siguiente: «Cuando los Patronatos la implantaron en el Colegio era practicada obligatoriamente por todos los Maestros y cuando otros $\mathrm{Pa}$ tronatos la negaban se hacía separación de niños y niñas en las clases». Los patronatos que la establecieron fueron los que gobernaron el Orfanato entre 1931 y diciembre de 1935 y el nombrado en marzo de 1936. Véase «Expediente de depuración del maestro Juan Camacho Castro», 1939-1940, educación, caja 33-13138 expediente 50, Archivo General de la Administración (AGA).
} 


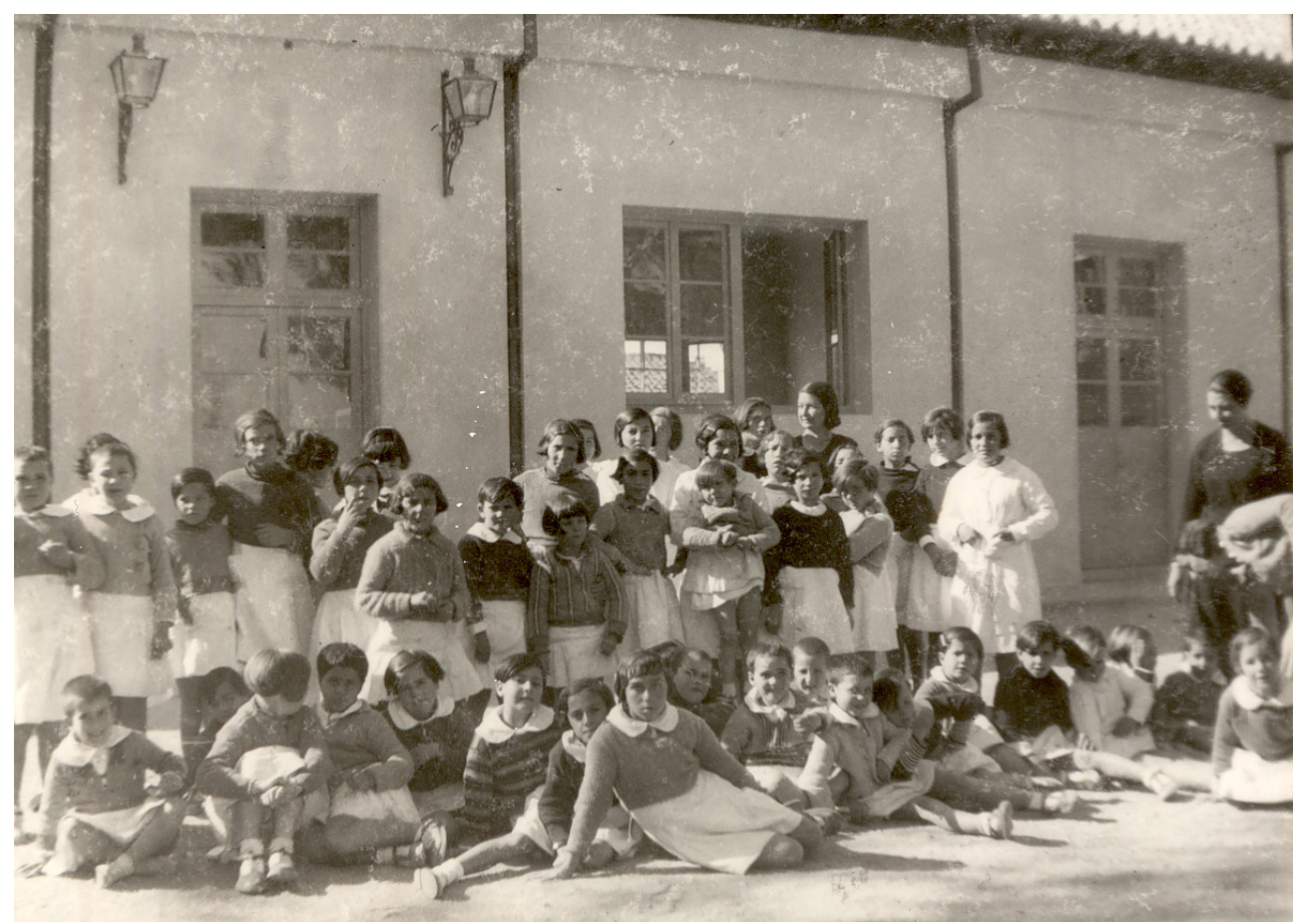

Imagen 6. Grupo de niñas acompañadas de personal docente en el Orfanato Nacional de El Pardo. 1935 (APCCAO).

Pasemos a continuación a analizar las características de las «escuelas nuevas» que se manifiestan en La composición literaria infantil. La Escuela Nueva hace trabajar de forma activa a los alumnos y la característica octava se refiere a la elaboración de trabajos libres:

8. La Escuela nueva provoca en los niños trabajos libres.

A. Concursos y exposiciones de trabajos de alumnos.

B. Desarrollo de los gustos particulares.

C. Desarrollo de la iniciativa mediante la obligación de elegir, pero con libertad de elección.

Carmen Conde propone que los niños realicen trabajos libres para mejorar su expresión verbal y escrita en los puntos quinto y, fundamentalmente, undécimo de su programa. En el quinto, el maestro comienza 
a pedir a sus alumnos que redacten cuentos de forma libre e individual. Los mejores relatos serían leídos en voz alta. Y en el penúltimo punto, el undécimo, se organiza la clase formando varios grupos de alumnos para estudiar una lección, permitiéndoles elegir libremente de entre los escritos por el maestro sobre el encerado. Finalmente, las lecciones serían explicadas por los propios alumnos a sus compañeros.

Son las características de los apartados «Vida intelectual» (11-15) y «Educación artística y moral»(26-30) las que se reflejan mejor en su programa. El rasgo undécimo hace referencia a la cultura general:

11. La Escuela nueva entiende por cultura general el cultivo del juicio y de la razón.

A. Método científico: observación, hipótesis, comprobación, ley.

B. Un conjunto de asignaturas obligatorias realiza la educación integral.

C. Nada de instrucción enciclopédica hecha de conocimientos memorísticos, sino desarrollo de la capacidad de encontrar en el medio ambiente y en los libros la materia de ejercicios para desenvolver, de dentro a afuera, todas las facultades innatas.

En La composición literaria infantil, Carmen Conde recurre al trabajo en los libros en los puntos quinto, décimo y undécimo. En todos ellos figura el aprendizaje a través los libros con los que cuenta la biblioteca escolar. En el quinto punto se pide a los niños que escriban y dibujen un cuento. Aquí sugiere que los niños acudan a la biblioteca para leer mucho y que trabajen sobre sus lecturas. ${ }^{73}$

\footnotetext{
${ }_{73}$ El Orfanato Nacional de El Pardo en 1935 contaba con una importante biblioteca. Durante el período que lo dirigió Dionisio Correas, 1931-1933, ya recibió una donación de libros por parte del Patronato de Misiones Pedagógicas. En los años siguientes las compras se sucedieron según los criterios de los maestros llegando a los mil ejemplares en 1935. Contaba con un catálogo impreso, ficheros, libro-registro de entrada, relaciones de lecturas y los ejemplares se ordenaban según la clasificación decimal de materias.
} 


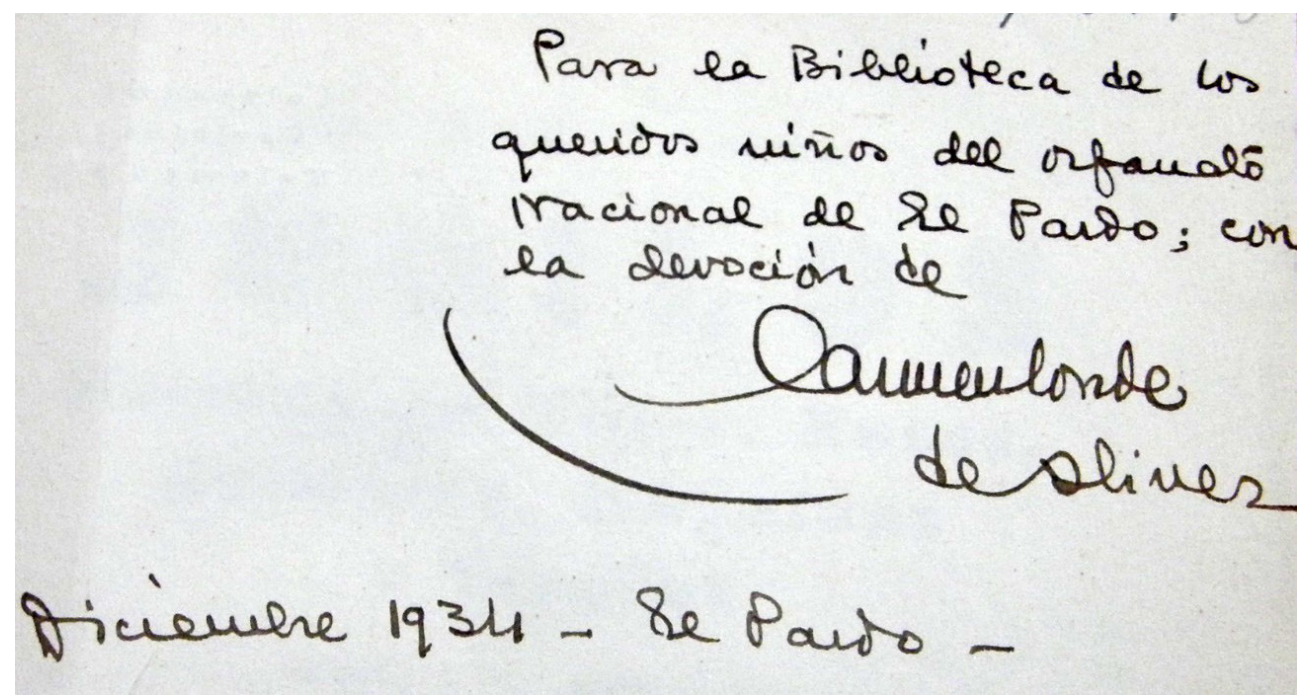

Imagen 7. Dedicatoria de Carmen Conde de un ejemplar de su libro Júbilos perteneciente a la biblioteca del Orfanato Nacional de El Pardo

(CEIP Isaac Peral, de Madrid).

En el décimo punto del programa, el maestro debe escribir en la pizarra los nombres de libros y autores que los alumnos podrán localizar en la biblioteca para preparar la lección. Además, enseñará a los niños el manejo de los ficheros del catálogo o las obras de referencia. El objetivo de este punto es que los alumnos «se muevan y adquieran el hábito de estar entre libros, y abrirlos a la busca de lo que les interese encontrar». ${ }^{74}$ En el undécimo punto, el maestro debe pedir a los alumnos que redacten un trabajo en grupo utilizando obras de la biblioteca.

El rasgo décimo cuarto hace referencia a la actividad personal del alumno:

14. La Escuela nueva recurre a la actividad personal del niño.

A. Asociación de un trabajo concreto a la mayor parte de los estudios abstractos.

${ }^{74}$ Conde, La composición literaria infantil, 33. 
B. Utilización del dibujo como ayuda de todas las ramas de estudio.

C. Se ha dicho: saber es prever. Con mayor razón se podría decir: saber es poder.

Esta característica es fundamental en el programa de Carmen Conde. La composición literaria infantil no sólo requiere el trabajo personal del alumno, sino que tiene como uno de sus ejes fundamentales el dibujo. Sirve como herramienta de comunicación por parte del maestro y como forma de aprendizaje. Únicamente se elude el recurso al dibujo en el punto sexto del programa. Al comienzo del curso los alumnos copiarán los dibujos que el maestro pinte en la pizarra. Pero según avanza el programa, el maestro les pide que dibujen y escriban más, ayudando así a desarrollar su imaginación. Uno de los ejercicios que propone la escritora y que repite en el curso de la Universidad Popular de Cartagena, es el de dibujar motivos en la pizarra para que, a partir de ellos, los niños inventen cuentos. 


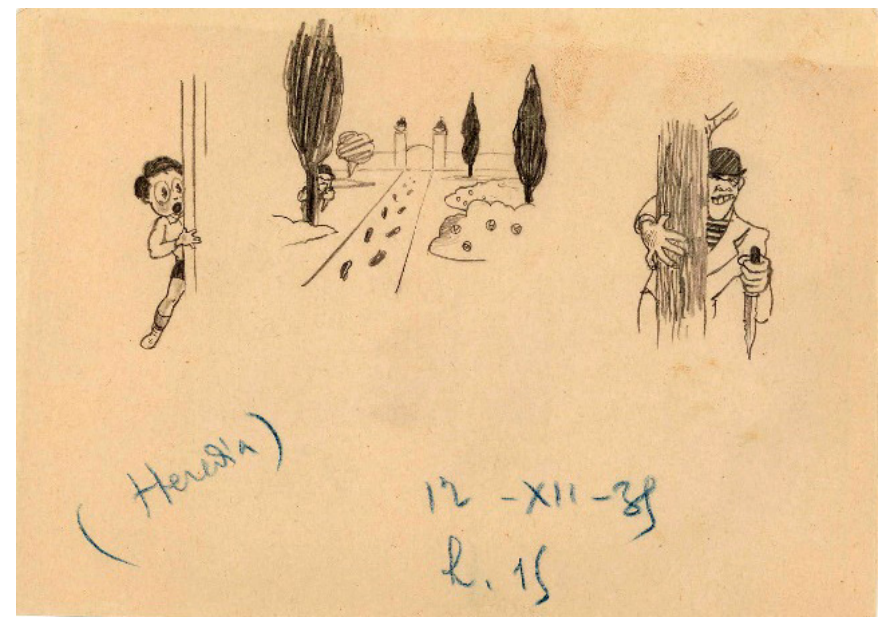

La villa re hallaba tran. gmila en la nothe, en el deshare ho un miño leia atentaments, enando ne oyerom muas pavod funtives of en la Newhana ge perfiló una sombra cimistina que empuñaba agyos enchillo, al verbol mino dejó eseapar un agnoo arito que mito ou alarima tood los habitomitas de la

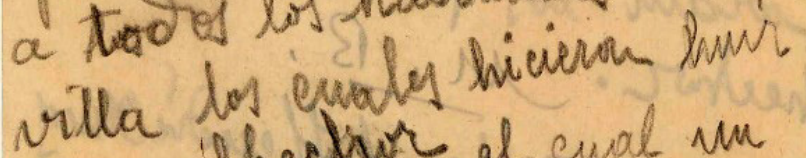
al mailheathe al cual nu pieco alejado of detriás de.

Imagen 8. Ejercicio del alumno de la Universidad Popular de Cartagena Manuel Heredia. Diciembre de 1935 (APCCAO). 
Estrechamente relacionadas con esta particularidad están las características décimo sexta y décimo séptima del apartado "Organización de los estudios». La primera hace referencia al trabajo individual de los alumnos mediante la investigación de documentos, su clasificación y, finalmente, la elaboración individual de documentos.

16. La Escuela nueva recurre al trabajo individual de los alumnos.
A. Investigación de documentos (en los hechos, los libros, los pe- riódicos, los museos).
B. Clasificación de los documentos (clasificadores por categorías, fichas, repertorios).
C. Elaboración individual de los documentos (cuadernos ilustra- dos, orden lógico de las materias, trabajos personales, confe- rencias).

Carmen Conde solicita la realización de trabajos personales por parte de los alumnos desde el punto primero de su programa. La investigación y clasificación de documentos los trabaja en el punto décimo. Ahí se enseña a los alumnos a encontrar lo que buscan en los materiales de la biblioteca escolar. Y la elaboración individual de documentos destaca especialmente en el punto duodécimo, el último de La composición literaria infantil. Para terminar el programa, el maestro solicita a cada alumno la redacción de una memoria entresacada de los cuadernos escolares y del diario de clase. Carmen Conde propone también la redacción de un diario oficial de la escuela, esto es, un diario de clase redactado cada semana por un escolar, y un diario de clase propio de cada alumno. ${ }^{75}$

El rasgo décimo séptimo alude al trabajo colectivo de los alumnos:

17. La Escuela nueva recurre al trabajo colectivo de los alumnos.
A. Reunir en común los materiales aportados sobre un mismo asunto por varios niños.

B. Determinar las asociaciones que en el tiempo y en el espacio sugiere el tema tratado.

\footnotetext{
75 Conde, La composición literaria infantil, 13.
} 
C. Determinar las aplicaciones de utilidad (en los niños) de sistematización científica (en los adolescentes).

Esta característica se pone en práctica en el punto undécimo del programa. Aquí el maestro debe organizar varios grupos que deberán trabajar un tema determinado con materiales previamente seleccionados.

La característica vigésimo cuarta trata de las recompensas:

24. La Escuela nueva actúa con recompensas o sanciones positivas.

A. Las recompensas consisten en buscar ocasiones a los espíritus creadores de aumentar su poder de creación.

B. Las recompensas se aplican únicamente a los trabajos libres y favorecen de este modo el espíritu de iniciativa.

C. No hay recompensas basadas en la competencia. En los juegos, el único premio es el mérito de la victoria.

Carmen Conde propone premiar las memorias redactadas tanto por el maestro encargado del programa como por sus alumnos. Respecto de las de los maestros, plantea premiar las mejores con «viajes de documentación a escuelas y países distintos»,76 mientras que las de los alumnos se podrán premiar con «una estancia en otra ciudad conociendo escuelas y niños diferentes, museos, cines, paisajes sobre todo». ${ }^{77}$

La característica vigésimo sexta de las escuelas nuevas se refiere a la emulación.

26. La Escuela nueva pone en juego la emulación.

A. La mutua ayuda, al invitar a la realización de servicios voluntarios, tiene una gran eficacia.

B. Este caso es el único en que se puede llevar un registro de notas o calificaciones apropiadas.

C. En todos los casos, hay que comparar el trabajo actual del alumno con su propio trabajo anterior y no con el de otro.

\footnotetext{
${ }^{76}$ Conde, La composición literaria infantil, 14.

77 Conde, La composición literaria infantil, 35.
} 
MODELO DE FICHA ESCOLAR QUE

PUEDE UTILIZARSE EN ESTE TRABAJO

\section{ESCUELA}

\section{CURSO $193 \quad-193$}

Ficha de

Tiempo que lleva en la escuela

Temperamento

Inteligencia

Indice moral

Observaciones

$\ldots$

(Anverso)

$-{ }^{15}$

(Ficha n. ${ }^{a} \mathrm{I}$, reverto)

Capacidad de trabajo.

Fechas del comienzo y final del cursillo

Progresos obienidos

Calificacion.

EL PROFESOR.

$16-$

Imagen 9. «Modelo de ficha escolar que puede utilizarse en este trabajo». ${ }^{78}$

${ }_{78}$ Conde, La composición literaria infantil, 10-11. 
La escritora recurre a ella en los primeros puntos del programa. En el punto segundo se escoge el mejor cuento de los escritos por los alumnos para leerlo en voz alta con el fin de que el resto lo compare con su propio trabajo. También propone un modelo de ficha escolar de los alumnos en la que se recogen, entre otros aspectos, los progresos obtenidos por cada uno de ellos. ${ }^{79}$ Finalmente, dice la poetisa «[q]ue aprendan [...] que HOY no puede parecerse a AYER como una gota a otra gota de agua. Cada día, un avance». ${ }^{80}$

La característica vigésimo séptima de la «escuela nueva» es que debe ser un medio estético.

27. La Escuela nueva debe constituir un medio estético.

A. Para esto, el orden es la primera condición, el punto de partida.

B. Los trabajos manuales, en particular los de arte industrial que se practican en estas escuelas, así como las obras de este género de que se vive rodeados, contribuyen a la belleza del medio ambiente.

C. Finalmente, el contacto con las obras maestras del arte y, en los alumnos con más aptitudes para ello, la práctica del arte puro satisfacen las necesidades estéticas de orden espiritual.

Para ello, la escuela debe promover el contacto con las obras maestras del arte. Carmen Conde ya abogaba por ello en 1931 cuando publicó Por la escuela renovada,$^{81}$ y lo aplicó en el punto noveno de su programa. En él, tras la proyección de una película educativa sobre un tema determinado, ${ }^{82}$ se pide a los alumnos que la relaten y dibujen. El maestro valorará la buena presentación de los trabajos en cuanto a caligrafía, puntuación, armonía y limpieza. Pero también apreciará el gusto en la elección de las palabras y la claridad y elegancia del lenguaje. Además,

\footnotetext{
${ }^{79}$ La ficha también recogía el nombre del alumno, el tiempo que lleva en la escuela, su temperamento, inteligencia, índice moral, observaciones, capacidad de trabajo, fechas de comienzo y final del cursillo y calificación.

${ }^{80}$ Conde, La composición literaria infantil, 27.

81 Conde, Por la escuela renovada, 71-80.

${ }^{82}$ Carmen Conde fue una de las personas responsables de la difusión del cine en el ámbito educativo. Por esta razón, fue miembro del Comité español del Instituto del Cinema Educativo.
} 
propone la lectura en voz alta de textos «de clásicos y de modernos, comparativamente, a fin de que se observe el progreso del idioma y su vertebración».83

El programa La composición literaria infantil: (escuela primaria) de Carmen Conde fue redactado en un momento en el que las teorías de la Escuela Nueva estaban en su apogeo en España. Por ello, vemos reflejada en esta obra multitud de caracteres de este tipo de escuelas, especialmente las de los apartados «Vida intelectual» y «Educación artística y moral». Además, el Orfanato Nacional de El Pardo, nacido como centro modelo, se organizó siguiendo buena parte de sus ideales.

\section{Nota sobre el autor}

JaVier Fernández Fernández es miembro del Cuerpo Facultativo de Archiveros, Bibliotecarios y Arqueólogos (Sección Archivos) desde 2009. Es licenciado en Historia por la Universidad Complutense de Madrid (2002) y en Documentación por la Universidad Carlos III de Madrid (2005). Como archivero ha trabajado en varios centros: el Archivo Municipal de Torrelodones, el Archivo Histórico Nacional, el Centro de Información Documental de Archivos y, desde 2013, se encuentra en el Archivo General de Palacio. Ha sido representante de la Subdirección General de los Archivos Estatales en el grupo de trabajo WP4 Standards and Guidelines del proyecto APEx (Archives Portal Europe network of excellence). En 2013 obtuvo el Máster Universitario en Memoria y Crítica de la Educación de la Universidad de Alcalá y UNED con premio a la excelencia académica. Actualmente realiza su tesis doctoral en el marco del Programa de Doctorado en Educación ofrecido por la Universidad de Alcalá bajo la dirección de María del Mar del Pozo Andrés. Sus líneas de investigación giran en torno a los orfanatos de la Escuela Nueva.

\section{REFERENCIAS}

Cegarra Salcedo, María y Carmen Conde. Epistolario: 1924-1988, ed. Fran Garcerá. Madrid: Torremozas, 2018.

${ }^{83}$ Conde, La composición literaria infantil, 31-32. 
Chamizo Vega, Chamizo. «El proceso de profesionalización de la enfermería en el Principado de Asturias». PhD diss., Universidad de Alicante, 2009.

Cobos, Pablo de A. Orfanato Nacional de El Pardo: [tres meses de director de estudios]. Segovia: Imp. Carlos Martín, 1934.

Conde, Carmen. La composición literaria infantil: (escuela primaria). Barcelona: Mujeres Libres, 1937.

Conde, Carmen. Por el camino, viendo sus orillas, vol. I. Barcelona: Plaza y Janés, 1986.

Conde, Carmen. Por la escuela renovada. Murcia: Universidad de Murcia, 1978.

Faria de Vasconcelos, Antonio. Una escuela nueva en Bélgica. Madrid: Francisco Beltrán, 1920.

Fernández Fernández, Javier. «La construcción de una casa de huérfanos modélica, el Orfanato Nacional de El Pardo (febrero de 1931-febrero de 1934)». Trabajo de Fin de Máster, Universidad de Alcalá, 2013.

Ferrière, Adolphe. "L'“École nouvelle" et le Bureau International des Écoles nouvelles». Pour l'Ère nouvelle 15 (1925): 2-8.

Ferrière, Adolphe. La práctica de la escuela activa: experiencias y actuaciones. Madrid: Francisco Beltrán, 1928.

Gutiérrez-Vega, Zenaida y Marie-Lise Gazarian-Gautier. Carmen Conde, de viva voz. Nueva York: Senda Nueva de ediciones, 1992.

Junta de Ampliación de Estudios. Memoria correspondiente a los cursos 1922-23 y 1923-24. Madrid: Junta de Ampliación de Estudios, 1925.

Moreno Martínez, Pedro Luis. «Carmen Conde y una ilusión: la educación del pueblo». En Carmen Conde: voluntad creadora (1907-1996), ed. Francisco Javier Díez de Revenga, 99-111. Murcia: Sociedad Estatal de Conmemoraciones Culturales-Ayuntamiento de Cartagena-Patronato Carmen Conde-Antonio Oliver, 2007.

Moreno Martínez, Pedro Luis. Educación popular en la Segunda República Española: Carmen Conde, Antonio Oliver y la Universidad Popular de Cartagena. Madrid: Biblioteca Nueva, 2008.

Sebastián Raz, José Manuel. «Luis Calandre Ibáñez. Su vida y obra (reivindicación de una figura ilustre de la medicina murciana)». PhD diss., Universidad de Murcia, 2010. 